\title{
Freire y el EZLN: la pasión por luchar y la dirección colectiva
}

\section{Miguel Escobar-Guerrero*}

De la misma manera que no puede existir una sola lectura del mundo, no es posible una única lectura de la praxis de Freire. En este artículo se presenta una experiencia de lectura de la realidad y construcción de conocimiento llevada a cabo con estudiantes de la Facultad de Filosofía y Letras de la UNAM. En ella se unen la praxis freireana (desde conceptos como lectura del mundo, praxis liberadora y conscientización) y la zapatista (desde el "iya basta!" y la "digna rabia” de las comunidades zapatistas), así como el psicoanálisis político (a partir de tres conceptos eje: eros, tánatos y apoderamiento, o poder), para construir pensamiento crítico transformador al juntar práctica-acción-teoría. Uno de los logros de esta experiencia es la sistematización de la metodología para el rescate de lo cotidiano y la teoría del aula (MRCyT), resultado de un proceso epistemológico interdisciplinario.
Palabras clave

Pedagogía freireana

Zapatismo

Psicoanálisis político

Globalización capitalista

Práctica revolucionaria

DOI: https://doi.org/10.22201/iisue.24486167e.2021.Especial.61022

* Profesor de tiempo completo en el Colegio de Pedagogía de la Universidad Nacional Autónoma de México (UNAM) (México). Doctor en Estudios del Desarrollo. Línea de investigación: lectura de la realidad en el aula (http://www.lrealidad.filos.unam. $\mathrm{mx}$ ). Publicaciones recientes: (2021), El hombre sin cabeza y la pedagogía erótica, México, UNAM-Facultad de Filosofía y Letras; (2020), ¿Es posible la lucha social en el salón de clases? La lutte sociale est-elle possible dans la salle de cours?, México, Ed. de Miguel Escobar-Guerrero, en: http://www.lrealidad.filos.unam.mx/Posible_luchasoc.pdf. CE: maeg@unam.mx 
Toda lectura de la palabra presupone una lectura anterior del mundo, y toda lectura de la palabra implica volver sobre la lectura del mundo, de tal manera que leer el mundo y leer la palabra se constituyen en un movimiento en donde no hay ruptura, en donde uno va y viene. Y leer el mundo junto con leer la palabra en el fondo significa reescribir el mundo.

Paulo Freire y Frei Betto, 1998

A mis estudiantes

\section{INTRODUCCIÓN}

En este trabajo comparto un proceso de construcción colectiva de conocimientos con apoyo de la praxis de Freire, el EZLN, el zapatismo, el psicoanálisis político y de mi propia praxis; a estos conocimientos los he identificado como problemáticos y como conceptos eje. En la mayor parte de la práctica logré trabajar con un equipo/colectivo llamado "lectura de la realidad", que fue parte del proyecto "La lectura de la realidad en el aula. Pensar la práctica para transformarla”, con Paulo Freire como el principal referente. ${ }^{1}$

Hemos (usaré ahora el plural, porque mi praxis ha sido colectiva) aprendido a enseñar-aprendiendo, de manera que buscamos siempre pensar nuestro pensamiento educativo y nuestra vida emocional, tarea que sólo fue posible en el equipo/colectivo. Nuestra práctica es semestral y anual, aunque las cuatro horas semanales asignadas es una limitación. ${ }^{2}$

Los logros más importantes aparecieron en el proceso de construcción de la metodología para el rescate de lo cotidiano y la teoría en el aula (MRCyT). Esta metodología surgió al buscar coherencia entre actuar-pensar-transformar. La MRCyT conjunta dos momentos epistemológicos del proceso de enseñar-aprender: el estudio de lo cotidiano y el hecho de tomar distancia para pensar el pensamiento. Era necesaria una práctica conjunta entre estudiantes y docente y para ello pusimos en marcha en el año 2007 los seminarios internacionales freireanos, hoy freireanos-zapatistas, que eran coordinados por el grupo de estudiantes, a la vez que compartían con otras instituciones procesos y resultados de sus estudios. ${ }^{3}$

En el México de hoy no se quieren estudiar las verdaderas causas de la destrucción de la vida toda por el capitalismo y la aparición de la pandemia de la COVID-19. El EZLN y las comunidades zapatistas nos anunciaron desde 2015 la tormenta en la que estamos:

Según nosotras, nosotros, zapatistas, la reflexión teórica, el pensamiento crítico tiene ese trabajo de centinela. A quien trabaja con el pensamiento analítico, le toca el turno de guardia en el puesto del vigía. Podría extenderme sobre

${ }^{1}$ Este proyecto inició en 1984 y se ha transformado en una línea de investigación permanente. La página del proyecto es: http://www.lrealidad.filos.unam.mx/

2 La materia se cursa en dos semestres en un año lectivo en el Colegio de Pedagogía de la Facultad de Filosofía y Letras de la UNAM; cada clase es de cuatro horas.

${ }^{3}$ Este trabajo se realizó en los XV seminarios internacionales freireanos-zapatistas en varias instituciones de México y en Valencia, España. 
la ubicación de ese puesto en el todo, pero por ahora sólo baste plantear que es una parte también, nada más, pero nada menos. Digo esto por aquéllos, aquéllas y aquélloas (no olvidar la equidad de género y el reconocimiento de la diversidad) que pretenden:

- O estar por encima y afuera del todo, como algo aparte, y se esconden detrás de la "imparcialidad", la "objetividad", la "neutralidad". Y dicen que analizan y reflexionan desde la asepsia de un imposible laboratorio materializado en la ciencia, la cátedra, la investigación, el libro, el blog, el credo, el dogma, la consigna.

- O trastocan su papel de vigías y se adjudican el de nuevos sacerdotes doctrinarios. Siendo apenas centinelas, se comportan como si fueran el cerebro dirigente que muta en tribunal penal a conveniencia. Y desde ahí ordenan lo que debe hacerse, juzgan y absuelven o condenan. Aunque hay que reconocerles que el hecho de que nadie les haga caso, marcadamente la realidad siempre rebelde, no los inhiba de su delirio (etílico, no pocas veces).

Bueno, el asunto es que lo que nosotros, nosotras, zapatistas, miramos y escuchamos es que viene una catástrofe en todos los sentidos, una tormenta (Subcomandante Galeano, 2015).

La Pedagogía del oprimido camina con el viaje por la vida del zapatismo. El proceso de concientización/pronunciamiento de los y las oprimidas irrumpió en la larga historia de resistencia y organización frente a la crueldad y agresión a su cultura, primero con la invasión colonial y en la actualidad con el neoliberalismo. Los pueblos del llamado Sur global tampoco se han quedado en la "cultura del silencio" que denunciaba y analizaba Freire. Desde Chile, Colombia y México, por citar algunos focos de resistencia, hasta la Europa rebelde, la lucha sigue y sigue. Por ello, en ese viaje por la vida una delegación zapatista, el Escuadrón 421, surcó los mares en su navío La montaña, desembarcó en España, recorrió Europa durante cuatro meses y regresó a México el sábado 12 de septiembre de 2021. Los medios realizaron una "amplia" cobertura de la travesía. Además de seguir juntando luchas en el proceso de concientización/pronunciamiento durante su recorrido, pronto llegará la delegación aerotransportada en la que viaja el subcomandante Moisés (Subcomandante Galeano, 2021).

En este contexto queremos compartir este escrito en el que juntamos la praxis freireana y la zapatista. Con su iya basta!, los zapatistas reconquistaron territorios y comenzaron una bella y creativa experiencia de autonomía; han resistido y se han organizado para luchar y destruir, a nivel global, la "hidra capitalista", que es la forma como el zapatismo nombra al capitalismo de guerra para simbolizar esas mil cabezas de un neoliberalismo que se niega a desaparecer. 
Cuando en 1978 se comenzaron a buscar alternativas para reinventar a Freire desde el aula (Escobar-Guerrero, 1990) nos dimos cuenta de la necesidad urgente de formarnos con un pensamiento interdisciplinario para "leer la realidad" en el aula. Con la aparición del EZLN el primero de enero de 1994 varias preguntas superaron nuestra concepción ontológica y epistemológica: ¿qué es leer la realidad y cuál?, ¿cómo percibimos y leemos la realidad?, ¿desde dónde la leemos y cómo lo hacemos? Sabíamos que la desinformación emitida por los medios de paga y el gobierno siempre han estado en contra de las luchas y movimientos sociales. También sabíamos que nuestra Facultad de Filosofía y Letras de la UNAM es, en general, muy conservadora, y que en ella se estudian esas luchas como fenómenos teóricos con poco compromiso real. De hecho, las referencias freireanas han ido desapareciendo.

Un primer desafío epistemológico lo encontramos en lo que posteriormente nombramos con el concepto de "mediación", cuando nos encontramos con la dificultad de entender con profundidad la relación entre las pantallas, en especial la televisión, en ese 1994, y la forma como se seguía anestesiando el razonamiento del pueblo mexicano y de sus llamados "intelectuales", docentes y administradores de la Facultad. Así comenzó nuestro camino interdisciplinario y logramos identificar y construir los siguientes conceptos:

- De Paulo Freire: lectura de la realidad, concientización/pronunciamiento, relación entre autoridad y libertad, la educación como acto de conocimiento y acto político, sombra del opresor introyectada, perversión neoliberal, luchas y movimientos sociales.

- Del EZLn y las comunidades zapatistas: ¡ya basta!, resistencia y organización, las cuatro ruedas del capitalismo (explotación, despojo, desprecio y represión), mandar obedeciendo, pensamiento crítico transformador, mujeres que luchan.

- Del psicoanálisis político: pulsión de vida, eros, pulsión de muerte, tánatos, pulsión de poder, percepción dela realidad, mediación, conducta psicopática, ataque al pensamiento, filicidio-parricidio-fratricidio.

- De Miguel Escobar-Guerrero: pedagogía erótica, relación entre construcción individual y colectiva de la praxis, erotismo de eros y erotismo de tánatos, libertad-autoridad-libertinaje-autoritarismo, norma y transgresión, alucinación, pedagogía de la imagen, luchas sociales en el aula (Escobar, 2001).

El movimiento zapatista entró al aula porque comprendimos que la mejor forma de entender la praxis freireana estaba en el seguimiento de las comunidades zapatistas. Al momento de escribir este texto (mayo-junio 2021) los zapatistas se encuentran en el "viaje por la vida", compartiendo las 
semillas de la vida en respuesta a una invitación de la Europa rebelde (Escobar y Navarro, 2021). Actualmente la lucha por la vida tiene otras prioridades en los procesos de concientización. Los malos gobiernos son capataces de sus patrones: el nuevo dios, el del dinero, no quiere perder nada de sus riquezas, sigue sin aceptar ningún cambio a su control del mundo (económico, cibernético, de espionaje). Mientras el planeta se sigue destruyendo se anuncian y ejecutan costosísimos viajes al espacio. La economía tiene que salvarse sin importar los costos en el ser humano. No se quiso cambiar ni una coma al modelo capitalista: lo importante es la sobrevivencia de la hidra capitalista.

Esta nueva realidad que se está viviendo no se entiende tampoco sin algo de imaginación, poesía y seducción a la sociedad para que despierte de sus alucinaciones:

Nada sé del destino de las letras con las que he intentado el asedio a vuestra gracia.

¿Acaso cegado habéis vuestro corazón para sombras no ver, ni mis ansias?

Siempre quise saber cuánta luna llevaba usted en los pechos, cuánto mar mamaba en sus entrañas, cuántas vidas parían sus labios, y cuántos sueños se escondían en sus caderas. Siempre quise saberle y conocerle, y llevar en mis manos el puente de su historia. Siempre quise querer y quererle y por eso de lejos marché para tenerle.

$[\ldots]$

Con la muerte será igual, porque creciendo somos más que el amor y sus rencores.

Me voy. A venir aspiro.

Sea.

Sombra, el guerrero (Subcomandante Marcos, 2007: Canto XI).

\section{Paulo Freire hoy}

¿Por qué el ser humano es una mercancía en la globalización? La racionalidad racional, técnica e instrumental

En el mundo de la globalización se impone un pensamiento único, una tramposa percepción de la realidad bajo un modelo educativo basado fundamentalmente en la trasmisión de conocimientos diseñados en coherencia con la concepción del ser humano reducido a capital humano. El estudiante es concebido como un sujeto individual - casi siempre un objeto- que debe memorizar contenidos programáticos, desarrollar hábitos y habilidades de competitividad y, por lo tanto, adiestrarse para eliminar a su competencia, adaptarse, ser eficiente y eficaz para optimizar las supuestas ventajas de una educación mercantil.

Y, como mercancía, el estudiante concebido como capital humano debe ser evaluado - de la misma forma que los docentes - según esta lógica reductiva donde los diseños y procesos de evaluación refuerzan (utilizando la 
terminología conductista) y/o persiguen la retroalimentación o realimentación de estudiantes y docentes dentro de un modelo establecido.

El proyecto de "lectura de la realidad" nos llevó a la construcción de una metodología para el rescate de lo cotidiano y de la teoría, $\mathrm{MRCyT}$, que se propone una concepción distinta del acto educativo, entendido como un acto de conocimientos y un acto político para pensar la práctica educativa y sociopolítica: el sujeto educativo no es un ser virtual, ni una mercancía vendible que se "educa" para salir a competir en el "mercado del desempleo" inherente al sistema capitalista.

La globalización ha logrado crear un mundo virtual, totalmente separado de la realidad real y expuesto a todo tipo de alucinaciones, es decir, a las fantasías que aparecen al no tener una adecuada percepción de la realidad; se genera así una información incorrecta sobre lo que acontece en la realidad real. Cuando no se tienen referentes empíricos para observar y analizar la realidad virtual, y para conectarla con la realidad concreta, emocional y/o social, se la percibe con las imágenes y fantasías que se producen sin aparente conexión, lo que puede convertirse en una percepción psicótica. El desempleo, la pobreza, el despojo y la represión en los sistemas macroeconómicos, por ejemplo, no existen sino como cifras: valores abstractos que obedecen a leyes de crecimiento económico.

Esto no quiere decir que no haya espacio virtual, por ejemplo, en los movimientos sociales, y que pueda ser un instrumento importante, como ha sucedido desde el ¡ya basta! de las comunidades zapatistas y su gran convocatoria nacional e internacional desde 1994 a la fecha. El espacio virtual, en especial de los celulares, fue de gran importancia en la movilización en los levantamientos populares de África del Norte y el movimiento de Indignados, en España y gran parte del mundo occidental, hasta Ocupa, en Estados Unidos.

Con los indignados de la tierra hemos de enfrentar la nueva política del azúcar y el garrote, de la corrupción y la represión macroeconómica que emplea el capitalismo corporativo, con sus aliados y subordinados. Frente a sus intentos de intimidación y corrupción universal blandiremos la moral de lucha y el coraje de los pueblos. Lo haremos, conscientes de que somos cada vez más, y de que serán cada vez más quienes en el mundo entero luchen por lo que en 1994 sólo parecía ser una rebelión indígena postmoderna y que en realidad es el principio de una revolución humana considerablemente mejor preparada para lograr la libertad, la justicia y la democracia a que todos aspiramos (González Casanova, 2011: 31).

En este contexto, la imposición de todo tipo de privatizaciones bajo esta lógica racionalista y técnica, y las reformas educativas en particular, van aún más lejos, porque al producir cortes con la realidad rompen, dividen (schizein en griego) y son esquizofrénicas. Separadas del mundo real, tales reformas buscan desconectar a docentes y estudiantes de la opresión social; llevarlos hacia las leyes virtuales con dobles mensajes y verdades a medias, con el apoyo 
perverso de los medios de comunicación de paga. Obviamente el doble mensaje es trasmitido y se utiliza para anestesiar a la sociedad, inmovilizarla. Esconde, por ejemplo, que en lo referente a la evaluación de procesos educativos, las preguntas pertinentes son: ¿quién decide qué?, ¿cómo?, ¿ a favor de qué y de quién? Y, por lo tanto, como diría Freire, ¿en contra de qué y de quién?

Uno de los resultados de ese proceso es impedir la comprensión y significado de las leyes que rigen la globalización capitalista en su derivación educativa. Al presentar la urgencia de calidad y evaluación de forma aislada, y esconder así las verdaderas necesidades e intenciones de capitalismo financiero bajo un mandato vertical y autoritario, se hace necesaria la exclusión de los estudiantes y docentes en particular, así como de la mayor parte de la sociedad. Esto quiere decir que no hay progreso si no se llega a producir una "buena mercancía" competitiva que sólo la privatización es capaz de impulsar y llevar a cabo. La exclusión, entonces, es necesaria; ya lo demostró Darwin en la selección natural de las especies que perversamente se quiere aplicar a la selección social.

\section{EL PSICOANÁLISIS POLÍTICO}

¿Cuál es la importancia de estudiar la percepción, la mediación, el ataque al pensamiento y la conducta psicopática?

Actualmente se planifican campañas encaminadas a controlar la percepción de la realidad: lo visible $=$ lo real = lo verdadero. Ésta es la ecuación que utilizan los medios de difusión mercantiles para atacarla, deformarla y trampearla: lo azul no es azul sino rojo, si esto responde a sus intereses. Se diseñan imágenes y discursos; se inducen alucinaciones y asociaciones donde se ataca la forma como se percibe la realidad, como decíamos, con verdades a medias, con dobles mensajes que inciden en el psiquismo; son cortes psicóticos de discursos que en el fondo favorecen al poder del dinero.

Para la construcción de la subjetividad es esencial entender este proceso de percepción de la realidad. Se cree que esto se consigue tan sólo con abrir los ojos: por ejemplo, con ver programas de televisión, pero no es así. Al percibir una realidad lo primero que hacemos es colocar alucinaciones, fantasías y fantasmas que forman parte de nuestro desarrollo emocional, es decir, investimos el objeto-imagen temporal y espacialmente.

Es necesario saber que, por ejemplo, el recién nacido es un ser indefenso que siente que la realidad puede destruirlo: existe en él la angustia de muerte y es la madre, real o sustituta, quien le enseña a leer la realidad, a corregir esa percepción tanática. Los medios de comunicación se aprovechan de esto para manejar el miedo y paralizar la acción humana. Y, desde luego, en ese proceso interviene también nuestra concepción ideológica: investimos, colocamos en la percepción de la realidad la concepción que tenemos - que nos han impuesto- de nosotros/as mismos/as, de la familia, la escuela, la religión, la política.

El mundo de la globalización - del espectáculo como mediaciónestá organizado por los dueños del dinero; claramente su interés es que la 
realidad se perciba de acuerdo con su ideología, y por ello trampean la realidad, con lo cual, además, manifiestan una conducta psicopática. ${ }^{4}$

De ahí la importancia y urgente necesidad de observar y estudiar la falsa percepción impuesta con la "mediación" de los medios de difusión mercantiles que esconde una conducta psicopática y conlleva un ataque al pensamiento del ser humano, individual y social que lo anestesia y paraliza para aislarlo de las luchas sociales, para impedirle organizarse y salir en defensa de la vida, de la justicia social, del hermano/a. Esta perversión va más lejos aún, pues no solamente se trata de aislar, sino de presentar a quienes organizan la resistencia y la protesta contra la concepción mercantil del mundo en general y, de la educación en particular, como grupúsculos que no entienden las ventajas de la globalización. El modelo capitalista no es el que no funciona; son los países y su fuerza de trabajo los que no tienen la capacidad de entender el mundo actual.

Un excelente ejemplo para estudiar la percepción impuesta por la globalización lo encontramos en la película Los juegos del hambre. ${ }^{5}$ El objetivo es criminalizar cualquier protesta social, y para ello se dejan abiertas las puertas a la represión y la crueldad del poder económico, el nuevo dios del dinero: la violencia contra quienes luchan se organiza como un mal necesario porque "el dinero trabaja en beneficio de las mayorías".

Pero esa falsa percepción ataca también la memoria social e individual: se busca desaparecer, ignorar y tergiversar. En esta película, por ejemplo, la rebelión contra el poder filicida se convierte en sentimiento de culpa, "obliga al poder" a recordarle al hijo/a rebelde su ofensa parricida sacrificando anualmente hermanos/as que compiten hasta matarse entre ellos/as. Sólo quedará un ganador/a. En la historia de la humanidad el filicidio se justifica por el parricidio.

La concepción epistemológica, ideológica, teórica, política y organizativa que subyace en la lógica no capitalista es totalmente distinta. En comunidades como las zapatistas, donde la subjetividad se construye colectivamente y el pensamiento, ligado al quehacer cotidiano, se hace solidario (digna rabia, por ejemplo), el ser humano tiene cuerpo y corazón, y está unido al corazón de la tierra, lo que se expresa en una nosotridad: un pensar y actuar conjuntamente fuera de la competencia mercantilista que alienta la superioridad de unos sobre otros y exige la eliminación del otro/a (Navarro, 2011).

\footnotetext{
${ }^{4}$ La conducta psicopática se puede identificar por su actuar agresivo; su finalidad es provocar un daño en la otra, el otro, a nivel individual y social: quien la expresa no tiene la capacidad de soportar la frustración que le produce el no apoderarse lo que quisiera. Por ello, decide tomarlos por la fuerza y apropiarse de lo que desea. Este comportamiento genera un daño social y/o individual porque siempre existirá una víctima despojada o dañada con esa conducta tanática.

${ }^{5}$ Los juegos del hambre (The Hunger Games), EUA, dirigida por Gary Ross y basada en el best-seller del mismo nombre de Suzanne Collins, 2012. La segunda parte se titula Los juegos del hambre: en llamas (Catching Fire: The hunger games 2), EEUU, dirigida por Francis Lawrence, 2013.
} 


\section{Paulo Freire, EZlN, Escobar y pSicoanálisis político}

\section{¿Cuál es el mundo para leer y transformar?}

En el contexto expuesto arriba, para analizar y posibilitar la construcción de la subjetividad tomamos como referente un postulado freireano: la lectura del mundo es anterior a la lectura de la palabra, y ésta es, a su vez, la continuación de la lectura mundo: leer y escribir el mundo es pronunciarlo, hacerlo nuestro para transformarlo, transformándonos a nosotros/as mismos/as. De ahí la relación que debe existir entre el texto escolar y el contexto sociopolítico.

Dentro de la praxis liberadora de Paulo Freire es necesario conocer y desarrollar la capacidad de conciencia crítica - concientizadora- que tiene el ser humano para construir su subjetividad, inserta en la sociedad. Es decir, debe aprender a leer su mundo: el de la explotación, de las relaciones de opresión no sólo económicas, sino emocionales (la neurosis social generada por ellas) y el de la miseria impuesta por la perversión del modelo capitalista, hoy en la era de la mundialización neoliberal. Pero, ese mundo es también de luchas, resistencias y organización: de la "digna rabia" de las comunidades zapatistas basadas en el respeto al diferente; de sueños y utopías; de deseos y seducción; de ese Eros y Tánatos tan mal conocidos y tan reprimidos desde la familia con el apoyo de la escuela, la religión, el aparato represivo; y también de lucha y resistencia contra los medios de desinformación y control del pensamiento.

Ahora bien, es necesario establecer que, como resultado de la evolución cultural, en la organización de las sociedades el derecho y las leyes surgen para reprimir, ordenar y regular su funcionamiento. La convivencia humana sólo es posible cuando los seres humanos se organizan para impedir que grupos aislados impongan su fuerza bruta. Éste es un paso decisivo en la evolución de las sociedades, como lo analiza Freud tanto en El malestar de la cultura como en su diálogo con Einstein en ¿Por qué la guerra? (1985).

El poder se impone con la violencia y se representa en el derecho, que siempre es una abstracción; y, por ser tal, su interpretación depende de quienes sean designados o se autodesignen para gobernar, como es el caso actualmente de quienes gobiernan el mundo globalizado: los dueños de los bancos, del mercado financiero, de las trasnacionales; los políticos, los beneficiarios de los paraísos fiscales, de los medios de información de paga, etc. El derecho y sus leyes se imponen por la fuerza, real o simbólica. Hoy se habla de la fuerza represiva del Estado, del monopolio de la violencia por quienes gobiernan: de la hegemonía de la violencia que ejercen, por ejemplo, los Estados Unidos.

Pero el derecho surge también como principio ético para controlar e impedir el retorno a la animalidad del ser humano, a la horda original, donde imperaba un solo poder absoluto. La ética es anterior al derecho y se constituye en los diques que se imponen para permitir el avance de las sociedades. Incesto, parricidio, filicidio y fratricidio conforman la racionalidad inconsciente: los deseos que, desde la pulsión de muerte, Tánatos, necesitan expresarse e 
imponerse constantemente para consolidar de nuevo un poder absoluto. De ahí que el otro poder celestial, como diría Freud, debe imponerse, es decir, Eros, como pulsión de vida, pero no como opuesto a Tánatos, sino en la dialéctica en la que caminan siempre juntos entre la trasgresión y la norma.

Con el movimiento de las prohibiciones, el hombre se separaba del animal. Intentaba huir del juego excesivo de la muerte y de la reproducción (esto es, de la violencia), en cuyo poder el animal está sin reservas. Ahora bien, con el movimiento segundo de la transgresión el hombre se acercó al animal. Vio en el animal lo que escapa a la regla de la prohibición, lo que permanece abierto a la violencia (esto es, al exceso), que rige el mundo de la muerte y de la reproducción (Bataille, 2003: 88).

En los análisis antropológicos de Georges Bataille y del psicoanálisis antropológico de Geza Roheim el ser humano avanza en su humanización entre la transgresión y la norma, entre la agresión y el sentimiento de culpa. En la horda original, una vez cometido el parricidio para defenderse del poder absoluto del padre, e instaurado el sentimiento de culpabilidad, esa trasgresión, el asesinato del padre, conduce a la imposición de leyes (totémicas): no al incesto ni a la exogamia. Podemos decir que detrás, y dando significado a la ley, se construye lo que conocemos como ética; ésta aparece y se impone para controlar los instintos primitivos de fuerza bruta y control absoluto: no al incesto y no al parricidio principalmente. A lo que podemos añadir, no al filicidio, no al fratricidio.

En nuestra lectura de la realidad en el aula, los análisis de Roger Dadoun y Fernando Martínez Salazar nos han permitido conocer, observar y estudiar que la energía fundamental que mueve a los seres humanos, a nivel individual y social, se puede sintetizar en tres pulsiones que se entrelazan mutualmente: eros, tánatos y apoderamiento o poder, que son conceptos eje del psicoanálisis político. Para nuestro análisis del poder absoluto del padre, que llamaremos el jefe, esta última es esencial, ya que es en ella donde las otras dos adquieren forma, y es hacia ella que se orientan y se controlan (Dadoun, 1995). Estas fuerzas son constitutivas del ser humano, hacen parte y conforman la esencia del cuerpo humano al cual se sujeta la construcción de la subjetividad, le dan forma y sentido; es decir, son el motor que mueve dialécticamente el desarrollo del cuerpo en la estructura emocional y sociopolítica de la sociedad.

Estas fuerzas siempre van juntas; son dialécticas, no dualistas: se hacen camino desde Eros hacia la vida, creciendo, compartiéndose, complementándose, pero son energías que también pueden hacer camino de regreso hacia la muerte, lo primitivo, la fuerza bruta. La energía libidinal de Eros puede imponerse a Tánatos o puede ser jalada desde Tánatos hacia la transgresión, el regreso a lo primitivo, y en esa lucha cotidiana aparece con toda su fuerza la pulsión de poder para imponer su dominio y control. Todo lo que Freire, basándose en Eric Fromm, citaba en Pedagogía del oprimido como biofilia y necrofilia. 
¿Por qué es esencial la mediación de la madre?

El ser humano construye su vida emocional conforme aprende a separarse de la madre, una vez dejado el seno materno. Aquí es importante señalar que no es sólo la figura del padre la que da las bases emocionales del ser humano, sino que la figura de la madre es esencial. Posiblemente en el desarrollo cultural y sociopolítico de las sociedades la figura del padre ha estado más cercana al poder de Tánatos, a la imposición de la "norma" y de las leyes que impone con la violencia y el sentimiento de culpa. Pero, la figura de la madre está más cercana a Eros, al crecimiento de la vida que ella misma vivencia desde su cuerpo. De ahí que para el ser humano en su crecer, la presencia permanente de la madre, como mediadora, es esencial; es ella quien enseña que puede hacerse dueño de sí mismo y conquistar su mundo externo e interno. El/la bebé realiza esta conquista entre sentimientos de abandono y presencia, entre amor y agresión, sufrimiento y consuelo. Y para superar ese abandono en el ser humano, aparece y se va constituyendo la pulsión de poder. Podemos decir que el/la niño/a busca su autonomía conforme aprende a separarse de la madre, para ello realiza emocionalmente un proceso que lleva al ser humano a sentir y saber que no es él quien depende de la madre, sino que es ella quien depende de él y la controla al manejar sus ausencias y sus desplazamientos.

Dadoun (1995) plantea que la pulsión de poder se constituye como si fuera la pulsión misma, alrededor de la cual se fijan la pulsión sexual y la pulsión de muerte, y que sostiene el imperio del ser humano como primera y última manifestación de vida. Para este autor, la política ofrece a la pulsión de apoderamiento su terreno principal de acción, ya que ella es, principalmente, expresión y ejercicio de la pulsión de poder y de la pulsión para el poder. Aquí encuentra una línea directa y brutal, el camino permanente para consolidarse e imponer su imperio, arrastrar y dominar o soltar, que es lo cotidiano de todo poder (Dadoun, 1995: 111-112).

En la política la pulsión de muerte se expresa vivamente y con voz inteligible: un político puede ser caracterizado por el campo de acción que entrega, activa o pasivamente, a la pulsión de muerte.

Pero en el cuerpo del ser humano existe y se expresa permanentemente la fuerza de Eros, que es el que convocamos para analizar y construir la subjetividad, a sabiendas de que debe aparecer e imponerse en contra del poder único del jefe, de la fuerza bruta de la horda originaria, que podemos identificar como la horda-moderna de la globalización. El cuerpo humano como templo de su subjetividad erótica debe encontrar sus caminos: su lucha convierte la esperanza en organización y no se queda en la pura espera, o sea, la lucha como digna rabia, fuerza colectiva de creatividad, encuentro, imaginación, respeto y crecimiento junto al otro/a, los otros/as. Esa es la fuerza de complemento, de energía libidinosa hacia la vida que ya no debemos dejar que se pervierta: es la fuerza de Eros individual y colectivo.

Existe una dialéctica inseparable entre la construcción de la subjetividad y la organización de la sociedad y su cultura: nos construimos en la 
relación dialéctica con el mundo, pero es necesario saber que nuestra subjetividad depende, en primer lugar, de las determinaciones sociales impuestas como normas y leyes a nivel familiar, escolar, cultural y sociopolítico.

En el desarrollo cultural e histórico los/as opresores han logrado consolidar el poder del "jefe”, el gran jefe dueño del gran capital, del dinero con sus bancos, su sistema financiero, sus trasnacionales, etc., que a su vez imponen en cada país su "mandato" hecho globalización. Quienes ahí gobiernan sólo obedecen esos "mandatos", con diferencias esenciales entre los países centrales dueños del dinero y los países periféricos. La pulsión de poder, hecha "mandato", es de opresión, explotación, despojo, represión y olvido dentro de una concepción del mundo dualista e impuesta de forma vertical, autoritaria y filicida. En ese engaño dualista y perverso esta concepción cuenta con el consenso tramposo de las elecciones, que defienden una supuesta democracia bajo el único "mandato" del bienestar del capital, nunca de las sociedades.

En la propuesta y construcción actual del mandar obedeciendo ejercido por comunidades como las zapatistas, la construcción de la ley es indispensable en el avance de la sociedad; ya no es el "jefe" que manda mandando, sino que existe una dirección colectiva que se construye en mandar obedeciendo y aprendiendo a gobernar con el mandato de la comunidad.

\section{¿Cómo construir la racionalidad emocional?}

Con la descripción de la horda paternal dominada por el macho con un poder ilimitado y el parricidio consumado por la banda de hermanos, un tercer elemento interviene para dar la fisionomía completa a la tesis freudiana de la Horda Original: el sentimiento de culpabilidad. Los hijos aman y admiran al padre de la misma manera que lo odian y tienen celos de él; la consumación de sus deseos de muerte desencadena una angustia profunda que los lleva a castigarse a sí mismos, reproduciendo la prohibición característica del totemismo... (Dadoun, 1972: 14).

El avance de la cultura, del derecho como justicia y represión, surgió para controlar a las minorías que, sin aceptar norma alguna, buscaban imponer su fuerza bruta, primitiva; la crueldad filicida del padre, del "jefe" (Dadoun y Escobar, 2013). Pero, en la actualidad, es una minoría, compuesta por los "dueños" del mundo de la globalización capitalista, la que trasgrede y la que impone a la mayor parte de la sociedad sus normas, su fuerza bruta, su horda primitiva-moderna: la ley del más fuerte, la del dinero, como expresión anal de un mal desarrollo emocional que en su paso de la etapa oral a la fálica, como expresión y construcción de su sexualidad individual y social, se fija, se estanca en esa etapa anal de guardar el dinero como control de su excremento para sí mismo. O sea, el avance cultural de las sociedades globalizadas va de regreso, posiblemente en regresión hacia la horda originaria - Tótem y Tabú- donde la pulsión de poder del padre, del "jefe", se imponía como única beneficiaria y controlaba también todos 
los placeres de vida y muerte, de Eros y Tánatos, imponiendo cruelmente su filicidio para mantener impunemente su poder sin dejar otra opción que el enfrentamiento y la muerte del padre, del "jefe": el parricidio como respuesta a esa crueldad absoluta, dualista.

Por ello, es esencial aprender a leer el mundo, a observar, conocer, analizar y construir la vida emocional, dialécticamente unida al desarrollo y la organización tanto de la estructura social como de la escolar y sociopolítica del ser humano. Es el estudiante, la estudiante, el ser humano, quien tiene que asumir la autonomía de su cuerpo, construir su subjetividad inserta en lo social, cultural, familiar, educativo; en la política. El ser humano no está dado, determinado; tiene que emerger como sujeto capaz de construir su subjetividad. Debe saber ser creativo para zafarse de las garras perversas del poder del gran hermano. Ese gran hermano con la cara oculta del poder filicida se hizo uno siendo fratricida. Ese hermano/a que manifiesta la sombra introyectada del opresor; esa misma sombra que nos llena del sentimiento de culpa indebido por desear la muerte del padre, de ese "jefe" que no está dispuesto a ceder nada de su necesidad de control absoluto. De su horda original-moderna genialmente representada, como ya decíamos líneas arriba, en la película Los juegos del hambre.

La sombra del opresor/a es introyectada en el ser humano con la violencia filicida; ataca el inconsciente y silencia la palabra como praxis transformadora. Se convierte en deseo de muerte y la deshumanización se entrelaza con deseos de eliminación parricida, fratricida, suicida. Y esa sombra se expresa como sentimiento de culpa.

Nuestra propuesta, lejos de ser neutra, es directiva; está inscrita en un proceso de educación emancipadora en favor y con - no para- las/os desarrapados del mundo, los y las oprimidas, los nadies. O sea que proponemos un camino de concientización sabiendo siempre que, como afirma Freire, "nadie concientiza a nadie; los seres humanos se concientizan - se educan- mediatizados por el mundo" y nuestro mundo es el de la explotación, el despojo, la represión capitalista, pero también el de luchas, resistencias y organización, el de la digna rabia propuesta en la praxis zapatista.

\section{¿PARA QUÉ SIRVE LA UTOPÍA?}

Aquí aparece otro concepto esencial para la construcción de la subjetividad: la utopía, que es la fuerza que nos da vida y nos ayuda a caminar; nos coloca en el horizonte de sueños inalcanzables, pero siempre posibles. La utopía se constituye en un deseo insaciable: como seres inacabados siempre necesitamos ir más adelante y, por ello, con la utopía no podemos bajar los brazos porque siempre estaremos en contra de la realidad social y emocional, en el sentido de que siempre puede y debe ser mejor.

Pero claro que la relación con un jefe o jefa autoritarios no es la misma que con jefes mediadores y amorosos, dispuestos a entender, conocer y enseñar $\leftrightarrow$ aprendiendo la afectividad de sus hijas/os; como tampoco lo es en la relación con sus hermanos/as reales o fantaseados: estas relaciones son 
de competencia como agresión por el amor de los padres, de constante búsqueda de eliminar al hermano/a hasta llegar al fratricidio real o simbólico si es necesario. Dice Fernando Martínez que

El acto de justicia también es producto de una renuncia pulsional a favor del otro y nace cuando se espera que sea correspondida de la misma manera. Es una transacción que tiene la característica de mantener en igualdad de circunstancias a dos o más seres humanos que tienen un mismo derecho y una misma obligación... Es una especie de arreglo que versaría así: no te elimino, siempre y cuando tú no intentes eliminarme a mí. Por esta razón, bien podríamos decir que la justicia no es sólo un acto de moralidad que nos dignifica, sino que es, además y ante todo, un acto que nace de la necesidad biológica de supervivencia. De ahí que cuando se comente una injusticia, se siente como un atentado contra la propia vida (Martínez, 1999:14).

En las relaciones familiares, cuando existe mediación amorosa de la madre y del padre, dispuestos siempre a demostrar su cariño, a impedir el deseo de eliminar al hermano/a, es más fácil aceptar las diferencias, controlar los deseos eróticos de Tánatos; al mostrar que amor y odio no son dualistas, sino que existen en todo ser humano, podemos controlar los deseos de eliminar al hermano/a pero siempre permanece el deseo mismo de hacerlo, que es lo que la globalización estimula.

La trampa dualista del parricidio analizada por Freud en la horda original está en dar énfasis al parricidio sin mostrar y resaltar el filicidio permanente del padre, que es el que provoca y luego maneja un sentimiento de culpabilidad indebidamente inserto en la estructura emocional del ser humano como sombra introyectada del opresor.

Pero este proceso no es así porque el primer acto, tanto en la horda original como en Edipo, es filicida. La huella inconsciente está mal desplazada y colocada en la culpa del hijo-hija que mata, real o simbólicamente, al padre. Y éste se hace menos culpable porque esa culpabilidad se desplaza en el enfrentamiento fratricida. El "jefe" sale indemne, como se puede observar claramente en Los juegos del hambre.

En la actualidad el gran hermano, espejo del "jefe" de la horda original, desplaza hacia nosotros una culpa indebida, pues quien nos vigila es el hermano; ya no se trata del dualismo filicidio-parricidio, sino de fratricidio, hermano-hermano. Este desplazamiento deja impune el filicidio porque ahora el problema es con el hermano/a y no con el "jefe".

Este dualismo es perverso, es la trampa del poder, de la autoridad autoritaria-filicida; de ahí la propuesta de trabajar dialécticamente el erotismo de Eros y el erotismo de Tánatos. La verdadera culpa estaría, tal vez, no en defendernos de esta perversión, en quedarnos callados/as, inmovilizados/as; sino en salir en defensa de nuestro erotismo de Eros, nunca como dualismo, siempre como postura de lucha dialéctica y, por lo tanto, creativa, sabiendo observar y analizar la fuerza bruta del “jefe”. Algo así como se narra en la Fábula del león del Viejo Antonio (Subcomandante Marcos, 1995). 
No es viable responder en forma dualista y primitiva al filicidio del “jefe”; lo que sí es necesaria es la organización de la resistencia sabiendo observar qué es y qué significa actualmente, desde la racionalidad racional y la racionalidad emocional: una regresión a la horda original. La parte primitiva del ser humano es dualista entre filicidio-parricidio, pero la organización de la digna rabia rompe ese dualismo, busca derrotar al “jefe”, al "león”, al sumirlo en sus contradicciones y amarrarlo en su propio goce filicida.

\section{¿Cómo caminan la utopía las/os zapatistas?}

Que dejemos eso del colectivismo (que, además, rima con primitivismo): que abandonemos esa obsesión por el cuidado de la naturaleza, el discurso de la madre tierra, la autogestión, la autonomía, la rebeldía, la libertad... Para los grandes medios de paga, ellos son los modernos, nosotros los arcaicos. Ellos son los civilizados, nosotros los bárbaros. Ellos son los que trabajan, nosotros los haraganes. Ellos son la "gente bien", nosotros los parias. Ellos los sabios, nosotros los ignorantes. Ellos son los limpios, nosotros los sucios. Ellos son los bonitos, nosotros los feos. Ellos son los buenos, nosotros somos los malos... Por eso su mundo se derrumba. Por eso el nuestro resurge, justo como esa lucecita que no por pequeña es menor cuando a la sombra abriga (Subcomandante Marcos, 2013, s/p).

Como lo hemos señalado a lo largo del escrito, la evolución cultural, social y educativa nos la ha impuesto el Tánatos del jefe filicida que, en su perversión, sabe cómo seguir estimulando e imponiendo el fratricidio y el parricidio. Por ello, entre otras cosas, el rechazo a cualquier tipo de "líder", de cualquier jefe que recuerde nuestra memoria, consciente e inconsciente; es decir que el rechazo a la vivencia de la autoridad-autoritaria es inminente. En las luchas de organización y resistencia no se quiere aceptar ningún tipo de jefe; en ocasiones ni siquiera de dirección colectiva. La desconfianza ante el engaño es casi total.

Sin embargo, la palabra-acción y presencia del vocero del EZLN siempre es bienvenida en nuestra lectura de la realidad: es necesaria para compartir y entender mejor la construcción de nuestras pequeñas luchas, así como para comprender mejor la zapatista. El sub nos ha propuesto siempre una "lectura" del mundo con creatividad, claridad, autoridad y coherencia en la nosotridad de la lucha de resistencia revolucionaria, en la esperanza que avanza en la organización lejos de vanguardia revolucionaria alguna, y de cualquier hegemonía. En el respeto a la diferencia, pero lejos de quedarse en el activismo, es decir, en la necesidad de pensar la práctica revolucionaria como praxis colectiva.

\section{La dirección colectiva tiene un referente de praxis esencial: Sexta Declaración de la Selva Lacandona}

No es posible esconder, ignorar y no reconocer la importancia del subcomandante Marcos/Galeano en esa praxis colectiva para entender mejor la lucha de su erotismo de Eros desenmascarando el erotismo de Tánatos. 
La perversión del poder que representa al jefe autoritario y filicida, el del poder del dios del dinero; esa maquinaria de guerra que marcha con las ruedas del capitalismo: explotación, despojo, desprecio, olvido. El ser humano necesita otro tipo de jefe y de jefa, padre y madre. Y Marcos/Galeano ha sabido estar presente cuando es necesario, aparecer y desaparecer, hablar y callar. Estar dispuesto a vivir y a morir si el camino de la lucha lo requiere. Espero que sea la sociedad rebelde la que decida si es necesaria su muerte simbólica, pero no su muerte real, en el deseo del poder filicida.

En el espacio de nuestro proyecto "La lectura de la realidad en el aula. Pensar la práctica para transformarla”, la praxis de Paulo Freire y la colectiva del Marcos/Galeano nos ha permitido leer mejor la realidad cultural, escolar, social, familiar, religiosa y política; a estar atentos para impedir el autoritarismo del jefe. En un momento de nuestra praxis este aprendizaje colectivo permitió el surgimiento del equipo de nuestro proyecto gracias al iya basta! El equipo ya no existe, pero ese iya basta! sigue hoy haciendo camino; es nuestra energía de vida y de esperanza en la lucha. Sigue guiando con su memoria histórica de resistencia, organización, dolor, muerte y utopía.

El subcomandante Marcos es quien, desde la hora primera de la larga noche en que los indígenas morían, recogió su dolor y su olvido. Él era y no era de esas tierras. En su boca hablan los muertos y en su voz camina la palabra de la dignidad indígena.

Es y no es en estas tierras: Votán Zapata, guardián y corazón del pueblo. Votán Zapata, luz que de lejos vino y aquí nació de nuestra tierra. Votán Zapata, tímido fuego que en nuestra muerte vivió 501 años. Votán Zapata, nombre que cambia, hombre sin rostro, tierna luz que nos ampara. Vino viniendo Votán Zapata. Estaba la muerte siempre con nosotros. Muriendo moría la esperanza. Viniendo vino Votán Zapata. Nombre sin nombre... Tomó nombre en nuestro estar sin nombre, rostro tomó de los sin rostro, cielo en la montaña es... Con este nombre son nombrados los sin nombre...

En fin, el sub es un ser humano cualquiera en este mundo: él es todas las minorías intoleradas, oprimidas, que resisten y dicen “iya basta!". El sub es todo lo que incomoda al poder y a las buenas conciencias (EZLN, 1994). Pero también es fruto de una experiencia colectiva, una de siempre mandar obedeciendo.

Durante estos veinte años también nos han mostrado que es posible - pese a los pesimismos, pese a muchos teóricos políticos y las marañas de tantos intelectuales que han negado salida alguna a esta catástrofe que se llama capitalismo, en su fase neoliberal- la construcción, en la práctica, de otras formas de vida; de otras formas de relaciones sociales y económicas; de otra forma de hacer política, contraria a los totalitarismos, no sólo de derecha, que intentan, a como dé lugar, imponer una unidad uniforme; han mostrado otra forma de hacer política, cuya fortaleza está basada en la diversidad de haceres y seres, de luchas, de resistencias. Han demostrado en estos veinte años que es posible la 
construcción de nuevos pensamientos, que no todo está dicho, y que se puede decir mucho más, más allá del pensamiento occidental eurocentrista; que se puede decir más desde los colores, olores y sabores de nuestras tierras, desde abajo, desde los excluidos de este sistema que resistimos (RvsR, 2013: s/p).

Estuve en la primera escuelita, allá en San Cristóbal, a mitad de año. Lo que escuché en las palabras y vi en la presencia física de los expositores y las expositoras zapatistas, jóvenes todos que a la hora de la insurrección tienen que haber sido niños, fue una tarea larga de organización humana, de cuadros como se diría en el lenguaje de la izquierda-, de hombres y mujeres que saben explicar y organizar para fines comunes y con palabras comunes para todos (Gilli, 2013: s/p).

Eso no se logra en un día o en un año. Requiere una larga paciencia, saber escuchar y comprender y una cierta humildad en quienes la practican. Arrogancia y soberbia son sus enemigos mortales; son esas virtudes de quienes nunca han organizado a nadie, ni en las malas ni en las buenas, pero han hablado y escrito mucho acerca de sus propias hazañas y personas (Gilli, 2013: s/p).

No junto mi voz a la de quienes, hablando de paz, piden a los oprimidos, a los harapientos del mundo, su resignación. Mi voz tiene otra semántica, tiene otra música. Hablo de la resistencia, de la indignación, de la "justa ira" de los traicionados y de los engañados. De su derecho y de su deber de rebelarse contra las transgresiones éticas de que son víctimas cada vez más (Freire, 1997: 97).

\section{REFERENCIAS}

Dadoun, Roger (1972), Geza Roheim et l'essor de l'anthropologie psychanalytique, París, Petite Bibliothèque Payot.

DAdoun, Roger (1995), La psychanalyse politique, París, PUF.

Dadoun, Roger y Miguel Escobar-Guerrero (2013), "Crueldad y utopía", París, en: http://ru.ffyl.unam.mx/bitstream/handle/10391/3896/R_Dadoun_M_Escobar_Crueldad_y_utopia_2013.pdf?sequence=1\&isAllowed=y (consulta: $22 \mathrm{de}$ mayo de 2021).

"El otro Paulo Freire: peregrino de lo obvio" (2008), entrevista a Miguel EscobarGuerrero [video] México, UNAM-FFyL, en: http://ru.ffyl.unam.mx/handle/10391/1412 (consulta: 22 de mayo de 2021).

Escobar-Guerrero, Miguel (1987), "La participación estudiantil. Dos experiencias educativas en el salón de clases. Una lectura freireana", Perfiles Educativos, núm. 35, pp. 22-37, en: https://www.iisue.unam.mx/perfiles/articulo/198735-la-participacion-estudiantil-dos-experiencias-educativas-en-el-salon-declases-una-lectura-freireana.pdf (consulta: 22 de mayo de 2021).

Escobar-Guerrero, Miguel (1990), Educación alternativa. Pedagogía de la pregunta y participación estudiantil, México, UNAM-FFyL, en: http://ru.ffyl. unam.mx/bitstream/handle/10391/654/1999_Educacion\%20Alternativa. pdf? sequence $=1$ \&isAllowed $=y$ (consulta: 22 de mayo de 2021).

EsсоваR-Guerrero, Miguel (2001), "Epílogo. La marcha de la palabra, hecha flor", en Miguel Escobar-Guerrero e Hilda Varela, Globalización y utopía, México, UNAM-FFyL, pp. 170-186, en: http://ru.ffyl.unam.mx:8080/jspui/bitstream/10391/653/1/2001_Globalizacion_y_Utopia.pdf (consulta: 22 de mayo de 2021). 
Escobar-Guerrero, Miguel (2020), ¿Es posible la lucha social en el salón de clases? La lutte sociale est-elle possible dans la salle de cours?, México, Miguel EscobarGuerrero, Ed., en: http://www.lrealidad.filos.unam.mx/Posible_luchasoc.pdf (consulta: 22 de mayo de 2021).

Escobar-Guerrero, Miguel y Fernanda Navarro (2021), De los mitos de la Antigüedad al dios del dinero: Prometeo, Antígona, Edipo Rey y Zapatismo, México, UNAM-Facultad de Filosofía y Letras.

EZLN (1994), Documentos y comunicados, vol. 1, México, Era.

EZLN (2005), "Sexta Declaración de la Selva Lacandona", Enlace Zapatista, en: http:// enlacezapatista.ezln.org.mx/sdsl-es/ (consulta: 22 de mayo de 2021).

Freire, Paulo (1997), Pedagogía de la autonomía, México, Siglo XXI.

Freire, Paulo y Frei Betto (1998), Essa escola chamada vida, São Paulo, Editorial Ática. Georges Bataille (2003), El erotismo, México, Tusquets.

Gilly, Adolfo (2013, diciembre 31), “En el veinte aniversario del ¡Ya basta!”, periódico La Jornada, Opinión.

GonzÁlez Casanova, Pablo (2011), "El movimiento de los indignados empezó en la Lacandona", en Gloria Muñoz Ramírez (comp.), Indignados, México, Ediciones Bola de Cristal, pp. 22-29.

Martínez S., Fernando (1999), "Freud, algunas de sus contribuciones a lo cultural y lo político”, Rompan Filas, núm. 43, pp. 26-33.

NaVARro, Fernanda (2011), "El otro prólogo", en Subcomandante Insurgente Marcos, Textos del subcomandante Marcos. Relatos del viejo Antonio, México, Ediciones Rebeldía, p. 14.

“¿Por qué la guerra? Carta de Albert Einstein a Sigmund Freud” (1985, mayo), Correo de la UNESCO, en: https://es.unesco.org/courier/may-1985/que-guerra-cartaalbert-einstein-sigmund-freud (consulta: 22 de mayo de 2021).

Red Contra la Represión y por la Solidaridad (RvsR) (2013, diciembre 31), "Saludo al vigésimo aniversario del levantamiento zapatista", Enlace Zapatista, en: http:// enlacezapatista.ezln.org.mx/2013/12/31/rvsr-saludo-al-vigesimo-aniversariodel-levantamiento-zapatista/?utm_source=feedburner\&utm_ medium=email\&utm_campaign=Feed\%3A+EnlaceZapatista+\%28Enlace+Zap atista\%29 (consulta: 22 de mayo de 2021).

Subcomandante Galeano (2015, abril 1), "La tormenta, el centinela y el síndrome del vigía”, Enlace Zapatista, en: http://enlacezapatista.ezln.org.mx/2015/04/01/latormenta-el-centinela-y-el-sindrome-del-vigia/ (consulta: 22 de mayo de 2021).

Subcomandante Galeano (2021, junio 27), "La travesía por la vida: ¿a qué vamos?", Enlace Zapatista en: http://enlacezapatista.ezln.org.mx/2021/06/27/la-travesiapor-la-vida-a-que-vamos/ (consulta: 22 de mayo de 2021).

Subcomandante Marcos (1995), "El león mata mirando", en EZLN, Documentos y comunicados 2: 15 de agosto de 1994-29 de septiembre de 1995, México, Era, Col. Problemas de México, pp. 33-35.

Subcomandante Marcos (2007), "Sombra el guerrero", en Noches de fuego y desvelo, México, Colectivo Callejero.

Subcomandante Marcos (2013), "Rebobinar 3", Enlace Zapatista, en: https://enlacezapatista.ezln.org.mx/2013/11/17/rebobinar-3/ (consulta: 22 de mayo de 2021).

Subcomandante Marcos (2000), "¡Oxímoron! La derecha intelectual y el fascismo liberal”, en: http://palabra.ezln.org.mx/comunicados/2000/2000_04.htm (consulta: 22 de mayo de 2021). 